\title{
The effect of nanosilica addition on flowability, strength and transport properties of ultra high performance concrete
}

\author{
Ehsan Ghafari ${ }^{\mathrm{a}, *}$, Hugo Costa $^{\mathrm{b}}$, Eduardo Júlio $^{\mathrm{a}}$, António Portugal ${ }^{\mathrm{c}}$, Luisa Durães ${ }^{\mathrm{c}}$ \\ a ICIST, IST-Technical University of Lisbon, Portugal \\ ${ }^{\mathrm{b}}$ ICIST, ISEC-Polytechnic Institute of Coimbra, Portugal \\ ${ }^{\mathrm{c}}$ Dept. of Chemical Engineering, University of Coimbra, Portugal
}

\section{A R T I C L E I N F O}

\section{Article history:}

Received 26 October 2013

Accepted 22 February 2014

Available online 1 March 2014

\section{Keywords:}

Ultra high performance concrete

Nanosilica

Pozzolanic reactivity

Microstructure

Transport properties

\begin{abstract}
A B S T R A C T
The experimental study herein presented was conducted aiming to evaluate the influence of nanosilica (nS) addition on properties of ultra-high performance concrete (UHPC). Thermo gravimetric analysis results indicated that $\mathrm{nS}$ consumes much more $\mathrm{Ca}(\mathrm{OH})_{2}$ as compared to silica fume, specifically at the early ages. Mercury intrusion porosimetry measurements proved that the addition of nS particles leads to reduction of capillary pores. Scanning electron microscope observation revealed that the inclusion of $\mathrm{nS}$ can also efficiently improve the interfacial transition zone between the aggregates and the binding paste. The addition of $\mathrm{nS}$ also resulted in an enhancement in compressive strength as well as in transport properties of UHPC. The optimum amount of cement replacement by nS in cement paste to achieve the best performance was $3 \mathrm{wt} . \%$. However, the improper dispersion of $\mathrm{nS}$ was found as a deterrent factor to introduce higher percentage of $\mathrm{nS}$ into the cement paste.
\end{abstract}

(c) 2014 Elsevier Ltd. All rights reserved.

\section{Introduction}

Ultra-high performance concrete (UHPC) is one of the most promising types of concrete, which has been developed in the last decade [1-3]. This innovative high-tech material is characterized by a dense microstructure, which presents both ultra-high compressive strength and ultra-high durability [4-5]. The main composition of UHPC contains a large amount of cement, usually between 800 and $1100 \mathrm{~kg} / \mathrm{m}^{3}$, which is around three to four times more than the quantity of cement in normal concrete [5]. Therefore, the blending of cement with high pozzolanic fine materials, such as nanosilica (nS), can be a suitable option to reduce the high volume of cement in the UHPC proportioning.

Nevertheless, the efficiency of UHPC is particularly dependent on its density. In fact, by optimizing the particle packing, an ultra-high consolidation of the concrete matrix can be reached. This can be obtained through an almost 'perfect' grain size distribution, by incorporating a homogeneous gradient of fine and coarse particles in the mixture. In this scope, the use of $\mathrm{nS}$ as pozzolanic addition is highly effective. Actually, due to its extremely small size particles, $\mathrm{nS}$ can fill the voids between cement and silica fume particles, leading to higher packing level ("filler" effect) and also generating a den-

\footnotetext{
* Corresponding author. Tel.: +351911831229.

E-mail addresses: ghafari@dec.uc.pt (E. Ghafari), hcosta@isec.pt (H. Costa), ejulio@civil.ist.utl.pt (E. Júlio), atp@eq.uc.pt (A. Portugal), luisa@eq.uc.pt (L. Durães).
}

ser binding matrix, with more calcium silicate hydrate (C-S-H). Consequently, a significant improvement on both durability and mechanical properties is obtained. Li et al. [6] showed that both the compressive and flexural strengths of concrete can be enhanced by incorporating nS. A concrete with addition of silica fume, fly ash and nS was also studied by Collepardi et al. [7]. It was concluded that concrete with this ternary combination has a better performance, in terms of both strength and durability, than those just with fly ash, but similar to those just with silica fume. Li [8] also found that an addition of $\mathrm{nS}$ results an increase in both early-age strength and long-term strength. Aly et al. [9] reported that incorporation of a hybrid combination of colloidal $\mathrm{nS}$ and waste glass into the cement mortars led to an enhancement of the mechanical properties in comparison with plain mortar.

Additionally, it has been proved that the incorporation $\mathrm{nS}$ also improves the durability properties of concrete. He and Shi [10] studied the chloride permeability and microstructure of Portland cement mortar with different types of nano-materials. This study confirmed that an addition of $\mathrm{nS}$ and nano-clay significantly improves the chloride penetration resistance as well as the general ionic permeability of cementitious mortar. An experimental study performed by Ji [11] showed that the addition of nano- $\mathrm{SiO}_{2}$ to the mixture improves the water permeability resistance of concrete.

Moreover, well-dispersed nano-particles act as centers of crystallization of cement hydrates, therefore accelerating the hydration [12]. Qing et al. [13] stated that the pozzolanic activity of 
Table 1

Chemical composition and physical properties of cement and silica fume.

\begin{tabular}{lll}
\hline Chemical analysis (\%) & Cement & Silica fume \\
\hline $\mathrm{SiO}_{2}$ & 20.9 & 93.6 \\
$\mathrm{Al}_{2} \mathrm{O}_{3}$ & 4.60 & 1.3 \\
$\mathrm{Fe}_{2} \mathrm{O}_{3}$ & 3.15 & 0.90 \\
$\mathrm{CaO}$ & 62.0 & 0.4 \\
$\mathrm{MgO}$ & 2.00 & 1 \\
$\mathrm{SO}_{2}$ & 3.60 & 0.4 \\
$\mathrm{~K}_{2} \mathrm{O}$ & $<1$ & 1.52 \\
$\mathrm{Na}_{2} \mathrm{O}$ & $<1$ & $<1$ \\
Specific gravity & 3.14 & 2.17 \\
\hline
\end{tabular}

nano- $\mathrm{SiO}_{2}$ is much higher than that of silica fume. It was found that the bond strength of the paste-to-aggregate interface, incorporating $\mathrm{nS}$, is higher than that of specimens with silica fume. A research also showed that the pozzolanic activity of fly ash significantly increases after incorporating $\mathrm{nS}$ [8].

There are several studies on incorporation of nS in concrete proportioning but most of them have focused on using $\mathrm{SiO} 2$ nanoparticles on mixtures with high values of water/cement ratio [8-17].

The present study aims to give a contribution in this field. In this scope, the pozzolanic activity of nS in UHPC mixture with very low water/cement ratio was studied. Pozzolanic activity of $\mathrm{nS}$ in cement pastes was studied as compared with silica fume using conductivity analysis, $\mathrm{x}$-ray diffraction (XRD) and thermo gravimetric analysis (TGA).

Additionally, the mechanical properties of several UHPC mixtures were characterized, namely by measuring the compressive strength. The evaluation of the fluid and gas transport properties of concrete specimens, including the water absorption, capillary water sorption, and gas permeability, was also performed. Mercury intrusion porosimetry (MIP) tests were conducted to characterize the size distribution of capillary pores in the UHPC specimens. Moreover, the microstructures of those were analyzed by scanning electron microscopy (SEM).

\section{Experimental study}

\subsection{Materials and mixtures proportions}

Portland cement type I 52.5R was used. An addition of silica fume (SF) presenting a specific area of $18.41 \mathrm{~m}^{2} / \mathrm{g}$ and an addition of $\mathrm{nS}$ with an average particle size of $15 \mathrm{~nm}$ were adopted. Table 1 shows some physical and chemical properties of cement and silica fume and Table 2 summarizes the properties of nS. The SEM micrographs of $\mathrm{nS}$ particles are also presented in Fig. 1, where it can be seen that nS particles exhibit a spherical shape. The aggregate used was siliceous sand with $0.6 \mathrm{~mm}$ of maximum aggregate size. The adopted admixture was a polycarboxylic acid based superplasticizer (SP) with solids content between 28.5 and 31.5 wt.\% and density between 1.067 and $1.107 \mathrm{~g} / \mathrm{cm}^{3}$.

In order to study the pozzolanic behavior of nS, three series of cement pastes with a very low water/cement ratio were considered. The cement pastes were designed and produced considering a water/cement ratio of 0.2 , in which $3 \%$ of cement was replaced by $\mathrm{nS}$ and SF. A control paste, containing only cement, was also produced to serve as reference paste. The properties of the cement pastes are shown in Table 3.

In addition, five series of UHPC mixtures containing different percentages of nS were prepared for this study. An optimized mixture proportion of UHPC, which was obtained through previous studies, was selected to serve as reference mixture [18-20]. Then, nS was incorporated as cement replacement by $1,2,3$ and 4 by wt.\% of cement. The large difference between the density of $\mathrm{nS}$ and silica

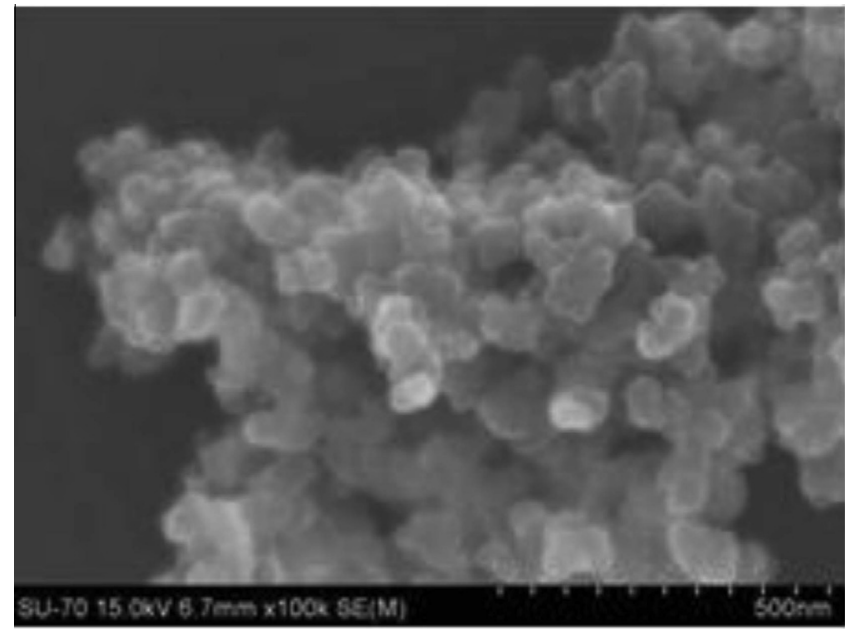

Fig. 1. SEM micrograph of nS particles.

fume resulted in an increase in the paste volume. The total content of powder was kept constant in volume. In addition, the water/powder ratio was kept constant for all mixtures. Table 4 shows the five series of mixtures, prepared with $\mathrm{nS}$ and a reference mixture without nS.

The mixing procedure involved several steps. First, in order to prevent agglomeration and also to promote uniform distribution of very fine particles, all powders and siliceous sand were mixed dry for 5 minutes at low speed. To incorporate dry nS would not have been possible, due to its very low density, causing particles to disperse in the air. Therefore, nS was first dissolved in water, the latter already containing the superplasticizer, and then gradually added to the mixture. After 5 minutes, the mixture became fluid. After mixing, the concrete was poured into the molds and, 24 hours later, it was demoulded. Then, the specimens were cured in water immersion at $20^{\circ} \mathrm{C}$ until the day of the test.

\subsection{Experimental test}

The experimental program of this study is divided into two main parts: first the pozzolanic activity of $\mathrm{nS}$ as compared with SF was studied by different methods; then, the effect of $\mathrm{nS}$ on fresh and hardened states and transport properties of UHPC was studied.

\subsubsection{Determination of pozzolanic reactivity of $n S$ and $S F$ in cement pastes}

Several techniques have been developed to study the pozzolanic activity of the materials but the determination of pozzolanic activity still presents considerable uncertainty being thus a complex problem [21-22]. In general these techniques can be classified into four main groups: electrical conductivity, quantitative X-ray diffraction analysis (XRD), thermo-gravimetric analysis (TGA) and chemical extraction.

The electrical conductivity method is a fast technique for evaluating the pozzolanic activity of materials. Raask and Bhaskar [23] applied this method for evaluating the pozzolanic activity of fly ash. This method allows the measuring of the amount of silica dissolved in a solution of hydrofluoric acid in which the active material is dispersed. This method requires 10 minutes for obtaining the pozzolanic index. Luxan et al. [24] proposed a faster method and pozzolanic index, given by the variation between the initial and final electrical conductivity of a calcium hydroxide pozzolanic suspension. The reaction between the calcium hydroxide and the pozzolanic material leads to a reduction in the electrical conductivity of the 
Table 2

Properties of $\mathrm{nS}$.

\begin{tabular}{|c|c|c|c|c|c|c|}
\hline Formula & Specific surface area $\left(\mathrm{m}^{2} / \mathrm{g}\right)$ & Purity & Crystal phase & Diamater (nm) & Density $\left(\mathrm{g} / \mathrm{cm}^{3}\right)$ & Morphology \\
\hline $\mathrm{SiO}_{2}(\mathrm{NS})$ & $160 \pm 20$ & >99.9 (\%) & Amorphous & $15 \pm 5$ & $<0.15$ & Spherical \\
\hline
\end{tabular}

Table 3

Compositions of the cement pastes (by weight of cement).

\begin{tabular}{lllll}
\hline Sample & Cement & SF & nS & W/C \\
\hline A0(control) & 1 & - & - & 0.2 \\
A1 & 1 & 0.03 & - & 0.2 \\
A2 & 1 & - & 0.03 & 0.2 \\
\hline
\end{tabular}

Table 4

Composition of UHPC mixture (by weight, $\mathrm{kg} / \mathrm{m}^{3}$ ).

\begin{tabular}{lllllll}
\hline Sample & Cement & SF & nS & Sand & Water & SP \\
\hline M0 (control) & 950 & 255 & - & 873 & 189 & 31 \\
M1 & 941.5 & 255 & 9.5 & 873 & 189 & 31 \\
M2 & 932 & 255 & 19 & 873 & 189 & 31 \\
M3 & 921.5 & 255 & 28.5 & 873 & 189 & 31 \\
M4 & 912 & 255 & 38 & 873 & 189 & 31 \\
\hline
\end{tabular}

suspension, which can be attributed to the fixation of dissolved calcium hydroxide by pozzolanic particles.

Recently, Paya et al. [25] proposed a method for evaluating the pozzolanic activity of fly ash, in which the pozzolanic activity of the material was calculated as the percentage of loss in conductivity at different reaction times (100, 1000 and $10000 \mathrm{~s})$. In the study herein described, a method similar to the one proposed by Paya [25] was used to evaluate the pozzolanic activity of both nS and SF. An unsaturated lime solution was prepared by dissolving 40 $\mathrm{mg}$ of $\mathrm{Ca}(\mathrm{OH})_{2}$ in $50 \mathrm{~mL}$ of deionized water. Afterwards, $5 \mathrm{~g}$ of pozzolanic material was added to the solution under constant stirring. A digital electrical conductivity and $\mathrm{pH}$ meter were used to record the variations in these parameters of the solution with time. In order to obtain the corrected conductivity curve, the procedure was repeated for the pozzolanic material added into $250 \mathrm{~mL}$ of deionized water. Finally, for an effective comparison, relative loss in corrected conductivity was calculated as percentage with respect to the initial conductivity value of lime-water solution before addition of pozzolanic material. A higher loss in conductivity is attributable to higher amount of lime fixation by the pozzolanic material.

In order to evaluate the direct pozzolanic activity of $\mathrm{nS}$ and SF, a TGA analysis was performed on dried samples. In this study, the progress of the pozzolanic reaction was monitored by measuring the amount of $\mathrm{Ca}(\mathrm{OH})_{2}$ content at 7, 28 and 90 days of age.

A TA instrument-Q500, equipped with data acquisition, was used for TGA analysis. Specimens which were cured in water and saturated in limewater were heated from 110 to $650{ }^{\circ} \mathrm{C}$, at a heating rate of $10{ }^{\circ} \mathrm{C} / \mathrm{min}$, in an inert $\mathrm{N}_{2}$ atmosphere. The amount of reacted (consumed) lime was determined by the weight loss measured in the TGA analysis. The pozzolanic reactivity was determined as the ratio of the consumed $\mathrm{Ca}(\mathrm{OH})_{2}$ to the initial $\mathrm{Ca}(\mathrm{OH})_{2}$.

The mineralogical characteristics of the materials were studied by means of XRD. X-ray diffractograms of powdered samples were obtained with a Panalytical (Philips) diffractometer x'pert MPD (in Bragg-Brentano), using Co $\mathrm{k} \alpha$ radiation. The data were collected from $4^{\circ}$ to $100^{\circ}, 1 \mathrm{~s}$ with step size of 0.025 and $1 \mathrm{~s}$ per step.

\subsubsection{Fresh and hardened states and transport properties of UHPC}

After the mixing was completed, tests were immediately conducted, still on fresh state, to measure the consistency of the UHPC. The consistency of the UHPC was measured using a flow table test,

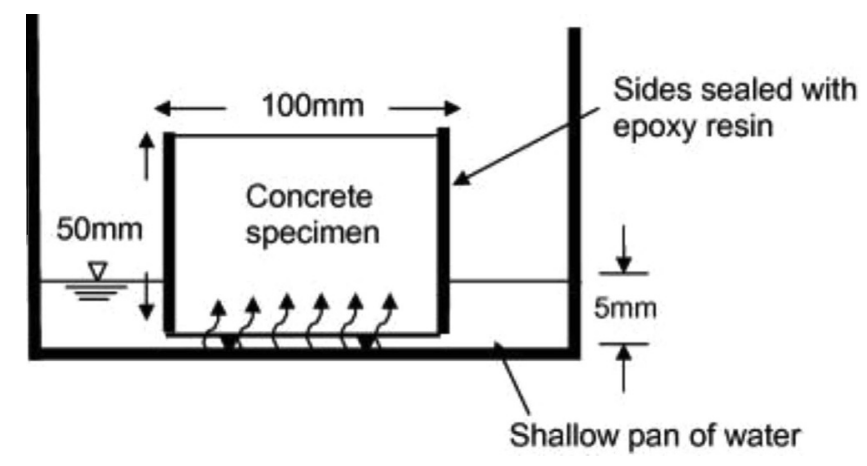

Fig. 2. Schematic diagram of sorptivity test.

according to ASTM: C1437. In this test, the mini slump cone is filled up, and then removed, allowing the concrete to flow outwards. Once concrete reaches a steady state, the flow table is dropped 20 times in approximately 20 seconds. Again, the concrete mass is allowed to settle, and then its average diameter is measured.

The assessment of axial compressive strength was performed at 7 and 28 days of age, using cubic samples $\left(40 \times 40 \times 40 \mathrm{~mm}^{3}\right)$, in accordance with the standard BS EN 196-1 [26]. The tests were performed on four specimens and the average values were considered.

While concrete is typically specified based on compressive strength and slump, it is well recognized that durability is most influenced by the transport properties of the concrete such as diffusivity, permeability, and sorptivity. The transport properties of concrete are governed by the characteristics of its pore structure [27]. Total porosity, pore size, pore connectivity, and pore saturation are all parameters that influence the transport coefficient [28]. Sorptivity and permeability, the main transport properties considered in this study, are both influenced by pore size and pore connectivity. Different mechanisms of liquid transport in the concrete were evaluated in this study, as described below.

The water sorptivity tests were performed according to the ASTM: C-1585 standard. At 28 days of age, three specimens, with standard dimensions of $100 \mathrm{~mm}$ diameter and $5 \mathrm{~mm}$ height, were prepared. Afterwards, the concrete specimens were oven dried at $105^{\circ} \mathrm{C}$, until a constant mass was achieved, following the drying procedure described in ASTM: C 642-06. The specimens were sealed and placed on the support at the bottom of the board container. The water level was maintained at 1-3 $\mathrm{mm}$ above the top of the support device. The schematic diagram of the sorption test is shown in Fig. 2 [29]. The mass increase in the specimens was measured at several times $(0,5,10,20,30,60,180,360,1440 \mathrm{~min})$; then, the sorptivity coefficient was measured using Eq. (1):

$I=A+K t^{1 / 2}$

where $K\left[\mathrm{~mm} / \mathrm{s}^{1 / 2}\right]$ is the water sorptivity coefficient, $I\left[\mathrm{~mm}^{3}\right]$ is the total volume of water absorbed and $A\left[\mathrm{~cm}^{2}\right]$ is the area of the specimen surface exposed to water. The initial rate of water absorption $(\mathrm{mm} / \mathrm{s})$ is defined as the slope of the line that best fits to I plotted against the square root of time $\left(\mathrm{s}^{1 / 2}\right)$. The initial slope of the straight line is taken as the water absorption coefficient.

Mercury intrusion porosimetry (MIP) tests were conducted to characterize the size distribution of capillary pores in the specimens. 


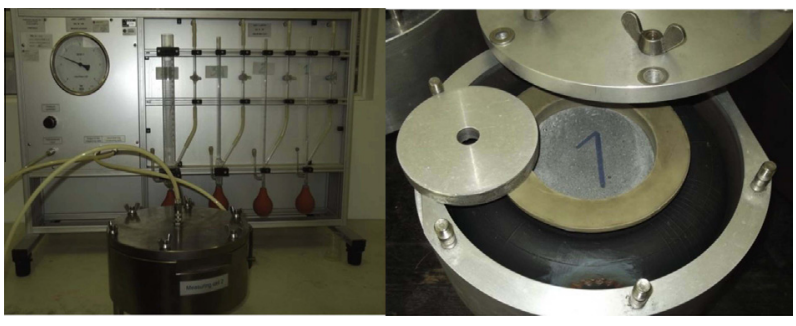

Fig. 3. Gas permeability apparatus and detail of a testing cell.

Mercury intrusion porosimetry (MIP) is widely adopted to characterize the pore size distribution of cement-based composites such as cement paste, mortar and concrete. The test can also provide information about the connectivity of pores. Each pore size is quantitatively determined from the relation between the volume of intruded mercury and the applied pressure [30]. The relation between the estimated pore diameter and applied pressure is generally expressed by the Washburn equation, as in Eq. (2):

$D=\frac{-4 \gamma \cos \theta}{P}$

where $D$ is the pore diameter $(\mathrm{nm}), \gamma$ is the surface tension of mercury (dyne $/ \mathrm{cm}$ ), $\theta$ is the contact angle $\left(^{\circ}\right.$ ) between mercury and solid and $P$ is the applied pressure (MPa). The test apparatus used for pore structure measurement was "Auto Pore III" mercury porosimeter. Mercury density is $13.5335 \mathrm{~g} / \mathrm{mL}$ and its surface tension was taken as 485 dyne $/ \mathrm{cm}$; the selected contact angle was $130^{\circ}$.

The maximum measuring pressure that can be applied is 200 $\operatorname{MPa}(30,000 \mathrm{psi})$, which means that the smallest pore diameter that can be measured reaches approximately $6 \mathrm{~nm}$ (on the assumption that all pores have cylindrical shape).

In order to provide the information about the pore size distribution of concrete, MIP test was performed on small-cored samples taken out from the specimens. The samples were then washed with acetone to terminate hydration. Before performing the test, the samples were also oven dried for $48 \mathrm{~h}$ to remove moisture of the pores.

The gas permeability stands as a critical material parameter, which characterizes the structure and the durability of concrete. The gas permeability test was performed according to "Rilem TC 116-PCD: Recommendations" [31]. For each mixture, three cylinder specimens with $100 \mathrm{~mm}$ diameter and $50 \mathrm{~mm}$ height were prepared. The cylinder specimens should be brought to the same moisture condition before the gas permeability test can be performed. In this scope, the specimens were stored in a laboratory atmosphere at $20 \pm 2{ }^{\circ} \mathrm{C}$ and $\mathrm{RH}$ of $65 \pm 5 \%$ for a period of 28 days. Specimens were then sealed with cellophane film and introduced into plastic containers, which are then properly sealed to reduce the evaporation of water from the specimen. The schematic experimental set up for measuring the gas permeability of concrete is illustrated in Fig. 3. This apparatus can be used for measuring values of the gas permeability in the range of $10^{-19}$ to $10^{-14} \mathrm{~m}^{2}$.

The gas permeability coefficient can be determined by Eq. (3) which is based on the Hagen-Poiseuille relation for laminar flow of a compressible fluid through a porous body with small capillaries and under steady-state conditions [32].

$K=\frac{2 Q P_{0} L \eta}{A\left(P^{2}-P_{a}^{2}\right)}$

where $k$ is the effective gas permeability coefficient $\left(\mathrm{m}^{2}\right), Q$ is the volume flow rate of the fluid $\left(\mathrm{m}^{3} / \mathrm{s}\right), A$ is the cross-sectional area of the specimen $\left(\mathrm{m}^{2}\right), L$ is the thickness of the specimen in the direction of flow $(\mathrm{m}), \eta$ is the dynamic viscosity of the fluid at test temperature $\left(\mathrm{Ns} / \mathrm{m}^{2}\right), P$ is the inlet pressure (absolute) $\left(\mathrm{N} / \mathrm{m}^{2}\right), P_{a}$ is the

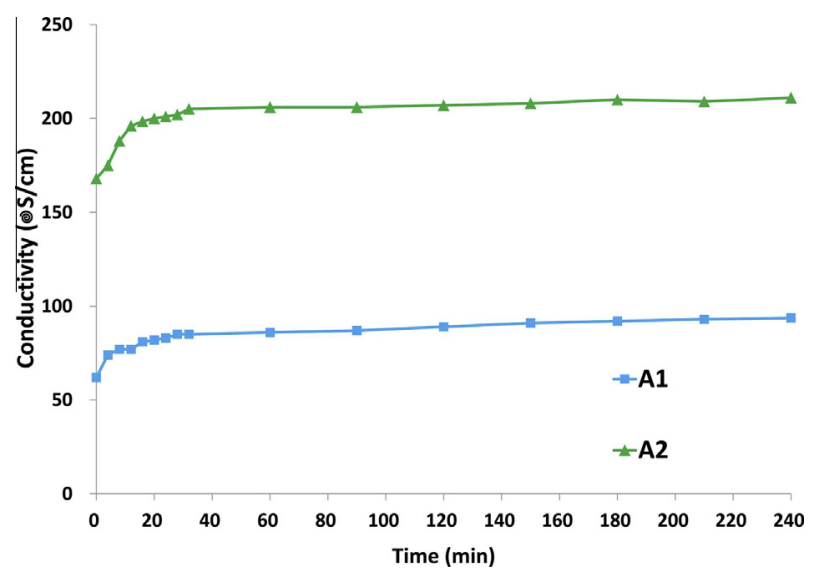

Fig. 4. Conductivity curve with time for pozzolan-water suspensions.



Fig. 5. Relative loss in corrected conductivity of lime-pozzolan-water suspensions

outlet pressure assumed in this test to be equal to atmospheric pressure $\left(\mathrm{N} / \mathrm{m}^{2}\right)$ and $P_{0}$ is the pressure at which the volume flow rate is determined, assumed in this test to be the atmospheric pressure Pa $\left(\mathrm{N} / \mathrm{m}^{2}\right)$

\section{Results and discussion}

\subsection{Pozzolanic reactivity of $n S$ and $S F$ in cement pastes}

The results analysis of the conductivity of the pozzolan-water suspensions are shown in Fig. 4. The incorporation of both $\mathrm{nS}$ and SF into water resulted in an increase in the suspensions conductivity, due to ions transfer from nS and SF into water. The nS-water suspension gave higher conductivity value than SF-water suspension due to its higher content of water-soluble ions.

Fig. 5 shows the relative loss in conductivity of lime-water-pozzolan suspension with time for both SF and nS additions. After adding $\mathrm{nS}$ and SF to this solution, the value of conductivity decreased with time, which implies that the concentration of both $\mathrm{Ca}^{2+}$ and $\mathrm{OH}^{-}$ions decreased with time. The main reason for this reduction can be attributed to the interaction between them and the pozzolanic materials that were added, which finally resulted in lime fixation due to the pozzolanic reactivity. The results indicated that, after 30 minutes only, the value of relative loss in conductivity reached $51 \%$ and $20 \%$ by adding $\mathrm{nS}$ and SF, respectively. As it is shown in Fig. 5 , nS showed a considerably higher reactivity than silica fume at early ages (31\%) which can be attributed to relatively higher specific surface areas of nS (Table 2) [33]. Although this effect became less significant by approaching the end of the 240 -minute testing period, it 


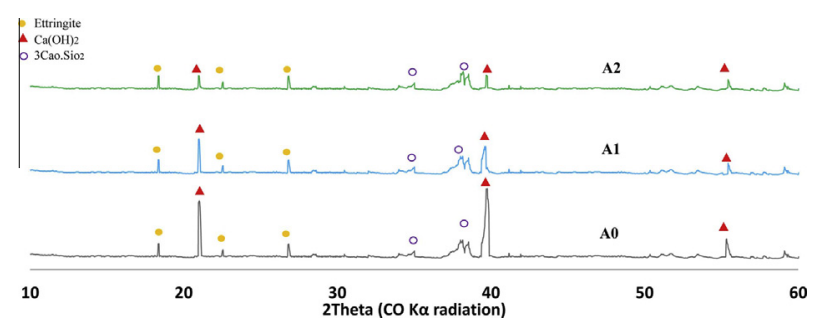

Fig. 6. Chemical compounds of $A 0, A 1$ and $A 2$ at 28 days, obtained from the XRD technique.

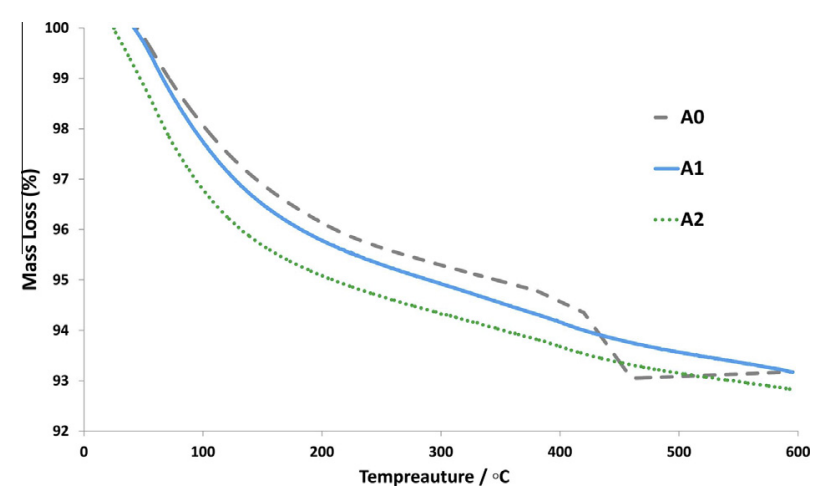

Fig. 7. TGA diagram for $\mathrm{A} 0, \mathrm{~A} 1$ and $\mathrm{A} 2$ at 28 days.

was observed that in the end the reactivity of nS was $21 \%$ higher than SF, which implies a higher pozzolanic reactivity of nS that SF.

The results of XRD of the cement paste with and without $\mathrm{nS}$ at 28-days of age are shown in Fig. 6. The pozzolanic activities of materials were compared based on $\mathrm{Ca}(\mathrm{OH})_{2}$ consumption which is obtained by the intensity variation of the main diffraction peaks. As it can be seen, the intensity of the crystal faces of $\mathrm{Ca}(\mathrm{OH})_{2}$ of A2 sample was considerably lower than that of the reference sample (A0). In fact, the intensity of crystal face of $A 2$ and $A 1$ cement paste sample is $65 \%$ and $60 \%$ lower, respectively than that of A0 sample. The results indicated that $\mathrm{nS}$ consumed $10 \%$ more $\mathrm{Ca}(\mathrm{OH})_{2}$ than the paste containing silica fume. Since some amount of $\mathrm{Ca}(\mathrm{OH})_{2}$ in hardened cement paste is in amorphous form, the amorphous consumption of $\mathrm{Ca}(\mathrm{OH}) 2$ cannot be well characterized by XRD analysis [34]. As a comparison, it is well-known that TGA analysis gives the most accurate results [35].

The TGA curves for three different cement pastes of A0, A1 and A2 at 28 days of age are shown in Fig. 7. The weight loss vs. temperature curve for hardened cement paste, between temperatures of $105-460{ }^{\circ} \mathrm{C}$, can be divided into two intervals. The mass loss in the first interval $110-380^{\circ} \mathrm{C}$ represents the decomposition of the hydration products, and the mass loss from temperature $380{ }^{\circ} \mathrm{C}$ and $460{ }^{\circ} \mathrm{C}$ is associated with dehydroxylation of the $\mathrm{Ca}(\mathrm{OH})_{2}$ [36]. As presented in Fig. 7, the values of mass loss for the A1 and A2 cement pastes samples are higher than A0 cement paste in the temperature interval of $110-380^{\circ} \mathrm{C}$, which is due to the formation of more hydrated C-S-H gel. The highest mass loss value of $61.18 \%$ is observed for the paste containing nS.

For the temperature interval of $380-460{ }^{\circ} \mathrm{C}$, it was observed that the incorporation of $\mathrm{nS}$ resulted in a decrease in the value of mass loss. The reduction of mass loss value in this interval implied the consumption of $\mathrm{Ca}(\mathrm{OH})_{2}$ due to higher pozzolanic activity of $\mathrm{nS}$.

The normalized amounts of consumed $\mathrm{Ca}(\mathrm{OH})_{2}$ in all the hardened cement pastes as a percentage of initially available $\mathrm{Ca}(\mathrm{OH})_{2}$ are shown in Fig. 8. The results indicate that after 90 days of curing, the $\mathrm{Ca}(\mathrm{OH})_{2}$ content in $\mathrm{A} 0$ sample increased, whereas in A1 and A2 sample the $\mathrm{Ca}(\mathrm{OH})_{2}$ content reduced with time. It can also be seen in

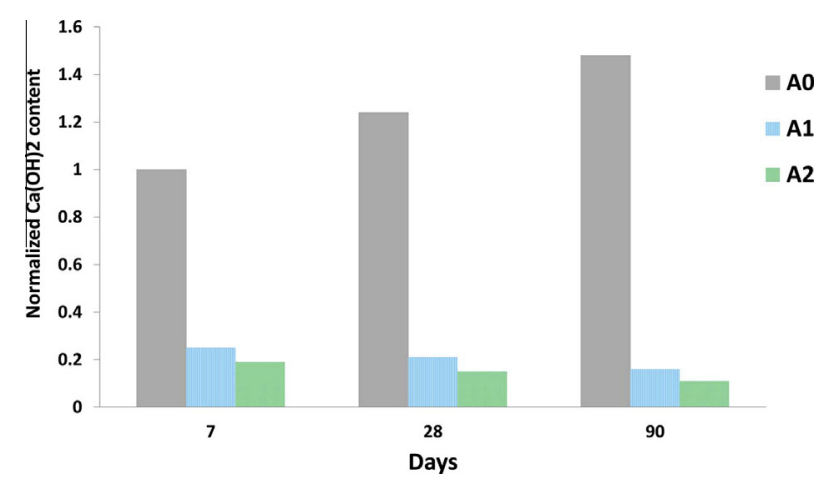

Fig. 8. The normalized $\mathrm{Ca}(\mathrm{OH})_{2}$ content of $\mathrm{A} 0, \mathrm{~A} 1$ and $\mathrm{A} 2$ cement pastes at 7,28 and 90 days.

Fig. 8 that the $\mathrm{Ca}(\mathrm{OH})_{2}$ contents of $\mathrm{A} 2$ and $\mathrm{A} 1$ samples at 7 days curing reduced by $73 \%$ and $81 \%$ respectively, compared to A0 sample, which is increased by $24 \%$. At the end of 28 and 90 days, nS consumed $85 \%$ and $89 \%$ of the initially available $\mathrm{Ca}(\mathrm{OH})_{2}$ which was $6 \%$ and $5 \%$ higher than the consumption amount by SF.

The TGA and XRD results confirmed the pozzolanic activity evaluation results from the electrical conductivity measurements of lime-pozzolan suspensions.

\subsection{Fresh and hardened state properties}

It is usually expected that the higher specific surface area of the $\mathrm{nS}$ imply an increase in water demand of concrete mixture, which can somewhat affect the workability. However, Collepardi et al. [37] studied the properties of self-compacting concrete containing $\mathrm{nS}$ and found out that the presence of nS makes the mixture more cohesive and reduces bleeding water and segregation, which finally improves the rheological behavior of concrete in fresh state.

The spread on the flow table results are also given in Table 5. The results apparently showed that there is a considerable decrease in slump flow values when $\mathrm{nS}$ (wt.\%) is incorporated into the mixture. The addition of $\mathrm{nS}$ (wt.\%) into the mortars had a significant effect on the water amount required in the mixture.

An incorporation of $1 \% \mathrm{nS}$ did not cause a significant change in the value of mini slump. However, mixtures with $\mathrm{nS}=2 \mathrm{wt} . \%$ and $\mathrm{nS}=3 \mathrm{wt} . \%$ show a reduction of $9 \mathrm{~mm}$ and $12 \mathrm{~mm}$, respectively, in the spread diameter in comparison with the reference mixture. A high reduction in spread value $(19 \mathrm{~mm})$ was observed by increasing the nS content from 3 to 4 wt.\%. In fact, a significant amount of water in the mix was absorbed by nS particles, which finally resulted in a significant decrease in workability. As a consequence, there is no sufficient water available for lubrication allowing particles free movement [38]. The obtained results in this study confirmed the fact that, for a constant volume of powder, the replacement of cement by a fine powder particle with high specific surface area will increase the water demand in order to maintain the workability of the mixture [39-40].

The average values of compressive strength at 7,28 and 90 days are shown, for all the specimens, in Fig. 9. The error bars indicate the standard deviations on the individual values. It can be seen that the addition of nano- $\mathrm{SiO}_{2}$ significantly increased the early-age compressive strength.

The addition of 3 (wt.\%) nS resulted in a 24\% increase at 7 days, which is $40 \%$ higher than that observed with the reference mixture. The higher compressive strength is due to faster pozzolanic reactivity of nanoparticles, in the presence of $\mathrm{Ca}(\mathrm{OH})_{2}$, making the microstructure denser. Additionally, the incorporation of $\mathrm{nS}$ particles can accelerate the hydration process of $\mathrm{C}_{3} \mathrm{~S}$ clinker phase due to the large and highly reactive surface of the nanoparticles [41-42]. 
Table 5

Slump, water absorption and MIP test results.

\begin{tabular}{|c|c|c|c|c|}
\hline \multirow[b]{2}{*}{ Samples } & \multirow[b]{2}{*}{ Slump (mm) } & \multirow[t]{2}{*}{ Water absorption (\%) } & \multicolumn{2}{|c|}{ MIP test } \\
\hline & & & Total porosity (\%) & Capillary pores (\%) \\
\hline M0 (control) & 193 & 1.212 & 6.35 & 2.65 \\
\hline M1 & 191 & 1.110 & 4.74 & 2.56 \\
\hline M2 & 184 & 0.95 & 4.66 & 2.44 \\
\hline M3 & 181 & 0.808 & 4.3 & 1.72 \\
\hline M4 & 174 & 0.856 & 4.8 & 2.33 \\
\hline
\end{tabular}



Fig. 9. Compressive strength (MPa) of nS particle blended concrete specimens.

However, the results showed that the addition of $\mathrm{nS}$ had a modest effect at the age of 28 and 90 days, so that the highest compressive strength was $144 \mathrm{MPa}$ and $148 \mathrm{MPa}$ for M3 specimen, which was only $8 \%$ and $6.5 \%$ higher than the reference mixture. This behavior confirms the fact that the most part of the pozzolanic reactivity of $\mathrm{nS}$ in cement paste is completed at early ages [33,43-44]. These results are consistent with the results of TGA and conductivity analysis.

It can be observed that the compressive strength increases with $\mathrm{nS}$ particles up to $3 \mathrm{wt}$.\% replacement. However, compressive strength decreased slightly when the replacement level reached $4 \%$ wt.\%. Thus, a higher replacement of cement by nS did not lead to an improvement in compressive strength, which can be due to improper dispersion of $\mathrm{nS}$ particles in the mixture. In fact nS particles, due to their high surface energy, have a pronounced tendency towards agglomeration. The dispersion of nanoparticles within the cement paste is a significant factor governing the performance of these products. When nanoparticles are added in excess to the mixture, these are not uniformly dispersed in the cement paste, and as a consequence week areas appear in the cement mortar due to agglomeration. Therefore, the disagglomeration of nanoparticles is crucial to achieve the composite materials with improved properties [12]. In addition, the amounts of $\mathrm{nS}$ in the mixtures can also have been exceeded the quantity required for consuming the $\mathrm{Ca}(\mathrm{OH})_{2}$ and this excessive amount of silica did not contribute to enhance the compressive strength. The insufficient workability of M4 can represent an extra cause for decreasing the compressive strength since there is no sufficient water available to contribute for lubrication which allows particles free movement.

\subsection{Microstructure and pore structure}

The obtained pore size distribution plot, covering the pore size range from around $400 \mu \mathrm{m}$ down to $5 \mathrm{~nm}$, is shown in Fig. 10. It can be seen that all MIP plots of mixtures containing nS stand slightly below the reference mixture (M0), particularly in the range 0.3-40 $\mu \mathrm{m}$, which corresponds to the capillary pores [38]. In this critical interval, M0 exhibited more cumulative volume of the pores, whereas M3 specimen had the lowest amount of pore volume in the

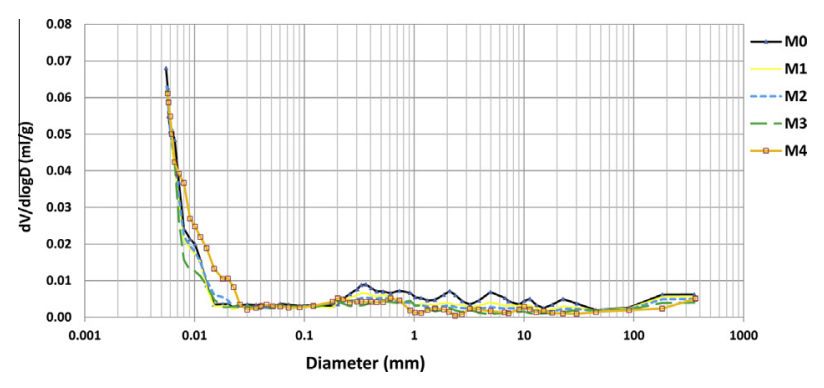

Fig. 10. Mercury intrusion porosimetry results.

mentioned range. In addition, all the specimens have much more pores ranging from $0.0006 \mu \mathrm{m}$ to $0.03 \mu \mathrm{m}$, which corresponds to the gel pores [45].

The amount of total pore volume and capillary pores is also presented in Table 5. Results showed that pore structures of M1, M2, M3 and M4 are finer than those of the reference mixture. It can be observed that by increasing $\mathrm{nS}$ content, the volume of capillary pores in specimens always decreases, which shows that the density of concrete is increased and the pore structure is refined. The incorporation of $\mathrm{nS}$ into the mixtures led to a decrease in total porosity up to $25.3 \%, 26.7 \%, 32.1 \%$ and $24.5 \%$, for M1, M2, M3 and M4 specimens, respectively. The results also indicated that M3 sample showed the lowest value of the capillary pores (1.72 vol.\%), which was $35 \%$ lower than the capillary pores content of M0 mixture. This can be due to the discontinuity of capillary pores by formation of more C-S-H gel.

The microstructures of the specimens were analyzed by scanning electron microscopy (SEM). Fig. 11(a) and (b) shows an overview of the microstructure of M2 and M0 using the same magnification. In general, the analysis of all images did not reveal any substantial differences in the microstructure of all specimens. However, it was found that the amount of capillary pores in M0 specimens was higher than in M3 specimens (see Fig. 11(b) and (c)). The incorporation of $\mathrm{nS}$ led to a further densification in the microstructure and to a concurrent reduction in capillary porosity of concrete mixtures. In comparison with M0 specimens, the microstructure of M3 specimens was very dense and few plated shape calcium hydroxide was observed. It is well known that portlandite, a mineral oxide, has a detrimental effect on bond strength of aggregates-to-paste [11], which causes a significant reduction in durability and in mechanical properties. Results showed that nS can effectively reduce the amount of portlandite, leading to a denser microstructure of interfacial transition zone (ITZ) between aggregate and paste. Insufficient bond between aggregate and paste was found in M0 specimens (see Fig. 11(c)), while a perfect binding paste-to-aggregates adhesion in M3 specimens (Fig. 11(d)) was observed, compared to M0 specimens (Fig. 11(c)).

\subsection{Transport properties}

The results obtained for water absorption are also presented in Table 5 . The addition of $\mathrm{nS}$ was found to be effective in reducing 

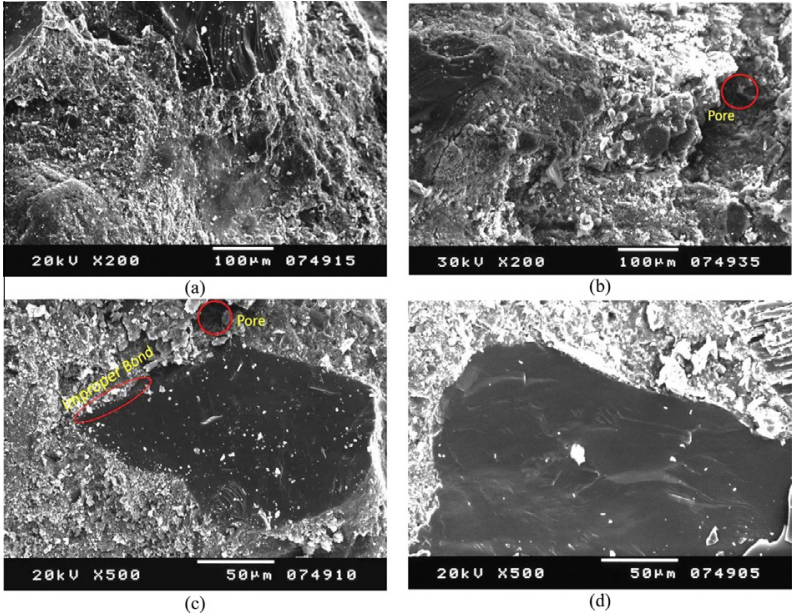

Fig. 11. SEM micrograph of UHPC mixtures at age of 28 days: (a) microstructure of UHPC-NS; (b) microstructure of UHPC; (c) interfacial transition zone (ITZ) microstructure between aggregate and paste in UHPC specimen; and (d) interfacial transition zone (ITZ) microstructure between aggregate and paste in UHPC-NS specimen.

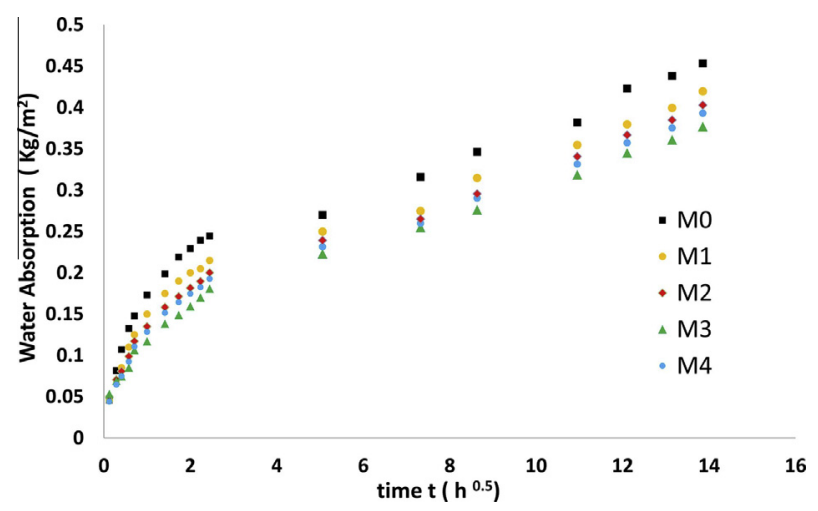

Fig. 12. Regression model of water sorptivity of specimens.

the water absorption. It can be seen that the amount of absorbed water in the samples decreased by increasing the $\mathrm{nS}$ content. The addition of nS by 1, 2, 3 and 4 wt.\% led to decreases in water absorption in samples by $8.5 \%, 21 \%, 33 \%$ and $29 \%$, respectively.

The results also showed that adding nS to cement paste mixes led to much lower sorptivity coefficient when compared to the reference mixture. In Fig. 12, the water absorption versus the square root of time is plotted for all mixtures. A nonlinear correlation was obtained for the data between $1 \mathrm{~min}$ and $6 \mathrm{~h}$, while a linear correlation was determined for the data between 1 and 7 days. Table 6 presents two different regression equations, determined by leastsquare regression for the time of $6 \mathrm{~h}$ before and the time of $24 \mathrm{~h}$ after. The initial rate of absorption cannot be determined since the data between $1 \mathrm{~min}$ and $6 \mathrm{~h}$ do not follow a linear correlation. However, the nonlinear regression plots (Fig. 12) along with nonlinear

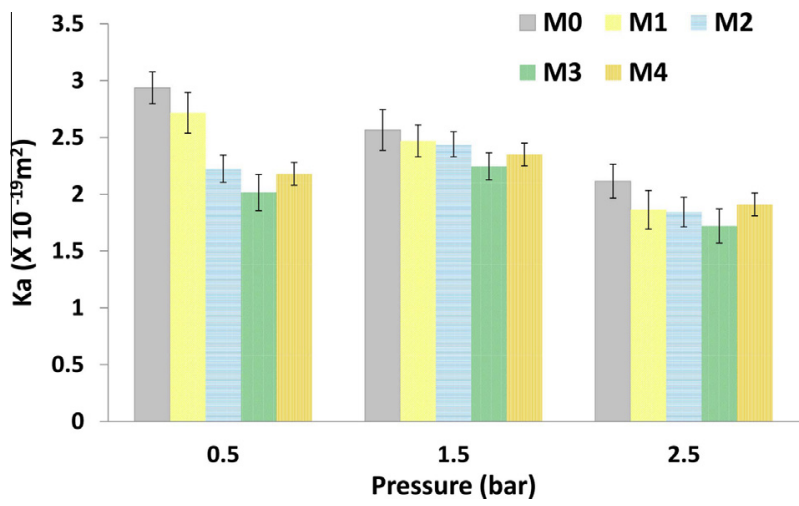

Fig. 13. Gas Permeability coefficient of specimens.

regression equations (Table 6) revealed that $\mathrm{M} 3$ specimens absorbed less water than the other specimens until $6 \mathrm{~h}$. The secondary rate of water absorption coefficients $\left(\mathrm{kg} / \mathrm{m}^{2} / \mathrm{h}^{0.5}\right)$ is defined as the slope of the line that is the best fit to water absorption plotted against the square root of time $\left(\mathrm{h}^{1 / 2}\right)$ using all the points from 1 day to 7 days. The very low sorptivity coefficient of $0.0178\left(\mathrm{~kg} / \mathrm{m}^{2} / \mathrm{h}^{0.5}\right)$ was obtained for the M3 specimens, which was 15\% lower than the reference mixture coefficient (M0).

The achieved results of water absorption and water sorptivity coefficient were in good agreement with capillary porosity values obtained by the MIP test. As sorption of water is mainly through capillary pores [46], therefore, the lower water absorption and sorptivity coefficient can be due to pore structure refinement and higher concrete compactness.

The gas permeability of three cylindrical specimens of each mix was measured at the same time by the 'cembureau' apparatus. The coefficients of gas permeability were obtained by performing the test with an inlet pressure of $0.5,1.5$ and 2.5 bar and are given in Fig. 13. The gas permeability coefficients of all the mixtures are within the same order of magnitude and the error bars indicate the standard deviations on the individual values. Regardless of the inlet pressure, results indicated that all mixtures containing nS (M1, M2, M3 and M4) showed lower gas permeability coefficients in comparison with M0 samples. The addition of $\mathrm{nS}$ to the mixture blends led to a decrease in gas permeability coefficient up to $7.5 \%$, $24.2 \%, 31.9 \%$ and $25.7 \%$ for M1, M2, M3 and M4 specimens, respectively. The maximum standard deviation measured for the individual values reached $0.18 \times 10^{-19} \mathrm{~m}^{2}$.

It has been found that the penetration of the gas mainly depends on the open porosity of the cement paste, the aggregates and the proportion of these two components in the mixtures [47], and with a higher porosity, gases can penetrate the concrete more easily [48].

The obtained results in this study revealed a strong relation between porosity of concrete specimens and the gas permeability coefficient. This relation has also been found for self-compacting concrete and high-volume fly ash concrete [48-49].

The results proved that the refinement of the pore structure of concrete was a key issue to improve the characteristics of concrete samples. In fact, most aspects of concrete durability are directly

Table 6

Regression equations for water absorption of UHPC mixtures, before $6 \mathrm{~h}$ and after $24 \mathrm{~h}$.

\begin{tabular}{|c|c|c|c|c|}
\hline Samples & Regression $\leq 6 \mathrm{~h} W_{a}\left(t^{0.5}\right)$ & Regression $>24 \mathrm{~h} \mathrm{~W}_{\mathrm{a}}\left(\mathrm{t}^{0.5}\right)$ & Correlation coefficient & Sorptivity coefficient $(>24 \mathrm{~h})^{\mathrm{a}}$ \\
\hline M0 & $W_{a}\left(t^{0.5}\right)=-0.0365 t^{2}+0.1718 t+0.0365$ & $W_{a}\left(t^{0.5}\right)=0.0209 t+0.1633$ & $R^{2}=0.99$ & 0.0209 \\
\hline M1 & $W_{a}\left(t^{0.5}\right)=-0.0299 t^{2}+0.1456 t+0.0313$ & $W_{a}\left(t^{0.5}\right)=0.0196 t+0.1422$ & $R^{2}=0.99$ & 0.0196 \\
\hline M2 & $W_{a}\left(\mathrm{t}^{0.5}\right)=-0.0203 t^{2}+0.1113 t+0.0360$ & $W_{a}\left(t^{0.5}\right)=0.0189 t+0.1386$ & $R^{2}=0.99$ & 0.0189 \\
\hline M3 & $W_{a}\left(t^{0.5}\right)=-0.0115 t^{2}+0.0817 t+0.0450$ & $W_{a}\left(t^{0.5}\right)=0.0178 t+0.1272$ & $R^{2}=0.99$ & 0.0178 \\
\hline M4 & $W_{a}\left(t^{0.5}\right)=-0.0120 t^{2}+0.0855 t+0.0471$ & $W_{a}\left(t^{0.5}\right)=0.0184 t+0.1319$ & $R^{2}=0.99$ & 0.0184 \\
\hline
\end{tabular}

${ }^{\mathrm{a}}\left(\mathrm{kg} / \mathrm{m}^{2} / \mathrm{h}^{0.5}\right)$ 
related with its porous structure, since capillary pores are responsible for fluids' migration in the concrete matrix. Therefore, as the value of capillary pores decreases, the resistance to aggressive environments improves significantly.

\section{Conclusions}

The experimental study herein described was conducted aiming to evaluate the pozzolanic behavior of $\mathrm{nS}$ and its effect on the microstructure of UHPC, as well as on its mechanical and transport properties. The following conclusions are highlighted:

(1) The incorporation of nS into cement paste with very low water/cement ratio can increase the amount of hydration products and thus it can cause a significant reduction in the amount of portlandite. It can be stated that nS with higher specific surface areas have higher rate of pozzolanic reactivity than $\mathrm{SF}$, at early ages. TGA results revealed that nS consume much more $\mathrm{Ca}(\mathrm{OH})_{2}$ as compared to SF.

(2) The addition of $\mathrm{nS}$ to the mixtures reduces the spread on flow table. The water demand in the mixtures also increases remarkably depending on the percentage of replacement. The highest amount of $\mathrm{nS}$ that can be incorporated keeping an acceptable range of slump flow is $3 \mathrm{wt} . \%$.

(3) Compressive strength of UHPC mixtures increased with the increase in $\mathrm{nS}$ content, especially at early ages. The optimum amount of cement replacement by $\mathrm{nS}$ in cement paste to achieve the highest compressive strength was $3 \mathrm{wt} . \%$. It was found that the proper dispersion of $\mathrm{nS}$ is a critical parameter to facilitate the incorporation of higher percentages into the cement pastes.

(4) The matrix phase of UHPC containing nS is significantly denser and more homogeneous than that of the reference mixture. MIP measurements revealed that the pore structure of UHPC can be effectively refined by adding nS. The addition of $\mathrm{nS}$ particles leads to a reduction in capillary pores and to a refinement of the pore structure. The SEM observation on the cement paste matrix, containing $\mathrm{nS}$, revealed that the extreme fine particles of $\mathrm{nS}$ act not only as a filler, but also as an effective pozzolanic material, since these react with $\mathrm{Ca}(\mathrm{OH})_{2}$ crystals, leading to an improvement in the pore structure. It was also concluded that the inclusion of $\mathrm{nS}$ can also efficiently improve the microstructure of the interfacial transition zone (ITZ) between the aggregates and the binding paste.

(5) Adding nS to cement paste mixtures results in lower water absorption and sorptivity, when compared to the reference concrete, which indicates that there is a lower number of capillary pores connections when additional hydration products are present, due to the pozzolanic reactivity of nS. The addition of $\mathrm{nS}$ is also considered to enhance the gas permeability resistance of UHPC. Porosity is identified as a key factor, which can govern the transport properties of UHPC.

\section{Acknowledgement}

The authors thank the financial support of the Portuguese Science and Technology Foundation (FCT) for the Project PTDC/ECM/ 098497/2008 entitled “Intelligent Super Skin (ISS)".

\section{References}

[1] Acker P, Behloul, M. DUCTAL ${ }^{\circledR}$ Technology: A large spectrum of properties, a wide range of applications. First International Symposium on Ultra High Performance Concrete. Kasesel, Germany 2004.
[2] M. Rebentrost, G.W. Experience and applications of Ultra-high Performance concrete in asiain Second International Symposium on Ultra High Performance Concrete. Kassel, Germany 2008.

[3] E. Fehling MS, S. Stürwald, editor. The Third International Symposium on Ultra High Performance Concrete and Nanotechnology for High Performance Construction Materials. Kassel, Germany: Kassel University Press March 2012.

[4] Graybeal BA. Material property characterization of ultra-high performance concrete. Federal Highway Administration Report No FHWA-HRT-06-103. August 2006. McLean, Virginia, USA.

[5] Richard P, Cheyrezy M. Composition of reactive powder concrete. Cem Concr Res 1995;25:1501-11.

[6] Li H, Xiao H, Yuan J, Jinping O. Microstructure of cement mortar with nanoparticles. Compos B: Eng 2004;35:185-9.

[7] Collepardi M, Collepardi S, Skarp U, Troli R. Optimization of silica fume, fly ash and amorphous nano-silica in superplasticized high-performance concretes. ACI Mater J 2004:495-506.

[8] Li G. Properties of high-volume fly ash concrete incorporating nano-SiO2. Cem Concr Res 2004;34:1043-9.

[9] Aly M, Hashmi MSJ, Olabi AG, Messeiry M, Abadir EF, Hussain AI. Effect of colloidal nano-silica on the mechanical and physical behaviour of waste-glass cement mortar. Mater Des 2012;33:127-35.

[10] He X, Shi X. Chloride Permeability and microstructure of portland cement mortars incorporating nanomaterials. J Transport Res Board 2008:13-21.

[11] Ji T. Preliminary study on the water permeability and microstructure of concrete incorporating nano- $\mathrm{SiO}_{2}$. Cem Concr Res 2005;35:1943-7.

[12] Sobolev K, Flores I, Hermosillo R, Torres-Martínez LM. Nanomaterials and nanotechnology for high-performance Cem Compos. ACI Mater J 2008;254:93-120.

[13] Qing Y, Zenan Z, Deyu K, Rongshen C. Influence of nano-SiO2 addition on properties of hardened cement paste as compared with silica fume. Constr Build Mater 2007;21:539-45.

[14] Beedle S, Groves GW, Rodger SA. The effect of fine pozzolanic and other particles on the hydration of C3S. Adv Cem Res 1989;2:3-8.

[15] Lothenbach B, Saout GL, Haha MB, Figi R, Wieland E. Hydration of a low-alkali CEM III/B-SiO2 cement (LAC). Cem Concr Res 2012;42:410-23.

[16] Jalal M, Mansouri E, Sharifipour M, Pouladkhan A. Mechanical, rheological, durability and microstructural properties of high performance selfcompacting concrete containing $\mathrm{SiO}_{2}$ micro and nanoparticles. Mater Des 2012;34:389-400.

[17] Beigi MH, Berenjian J, Omran OL, Nik AS, Nikbin IM. An experimental survey on combined effects of fibers and nanosilica on the mechanical, rheological, and durability properties of self-compacting concrete. Mater Des 2013;50:1019-29.

[18] Ghafari E, Bandarabadi M, Costa H, Júlio E. Design of UHPC using artificial neural networks. In: 10th International symposium on brittle matrix composites. Warsaw, Poland 2012.

[19] Ghafari E, Costa H, Júlio E. Design of UHPFRC with Enhanced Ductility 8 th Rilem conference on fiber reinforced concrete. Guimares, Portugal 2012.

[20] Ghafari E, Costa H, Júlio E, Portugal A, Durães L. Optimization of UHPC by adding nanomaterials 3 nd international conference on ultra high performance concrete 2012. Kassel, Germany. 71-79.

[21] Kendrick DA, Parsonage JR, Vazifdar R. Interaction of alkali and alkali earth metal hydroxides with microsilica. Cement and Concrete Research 1998;28:1537-44.

[22] Mostafa NY, El-Hemaly SAS, Al-Wakeel EI, El-Korashy SA, Brown PW Characterization and evaluation of the pozzolanic activity of Egyptian industrial by-products: I: Silica fume and dealuminated kaolin. Cem Concr Res 2001;31:467-74.

[23] Raask E, Bhaskar MC. Pozzolanic activity of pulverized fuel ash. Cem Concr Res 1975:363-75.

[24] Luxán MP, Madruga F, Saavedra J. Rapid evaluation of pozzolanic activity of natural products by conductivity measurement. Cem Concr Res 1989;19:63-8.

[25] Payá J, Borrachero MV, Monzó J, Peris-Mora E, Amahjour F. Enhanced conductivity measurement techniques for evaluation of fly ash pozzolanic activity. Cem Concr Res 2001:41-9.

[26] CEN EN 196-1. Methods of testing cement-Part 1: Determination of strength, European Committee for standardization 2005.

[27] Bentz DP, Clifton JR, Ferraris CF, Garboczi EJ. Transport properties and durability of concrete. Maryland: National Institue of Standard and Technology; 1999.

[28] Garboczi EJ. Permeability, diffusivity, and microstructural parameters: a critical review. Cem Concr Res 1990;20:591-601.

[29] Sabir BB, Wild S, Farrell MO'. A water sorptivity test for martar and concrete. Mater Struct 1998;31:568-74.

[30] Tanaka K, Kurumisawa K. Development of technique for observing pores in hardened cement paste. Cem Concr Res 2002;32:1435-41.

[31] RILEM TC 116-PCD: Permeability of concrete as a criterion of its durability. 1999. p. $163-73$.

[32] Kollek JJ. The determination of the permeability of concrete to oxygen by the Cembureau method-a recommendation. Mater Struct 1989;22:225-30.

[33] Madani H, Bagheri A, Parhizkar T. The pozzolanic reactivity of monodispersed nanosilica hydrosols and their influence on the hydration characteristics of Portland cement. Cem Concr Res 2012;42:1563-70.

[34] Berger RL, Mcgregor JD. Effect of temperature and water-solid ratio on growth of $\mathrm{Ca}(\mathrm{OH})_{2}$ crystals formed during hydration of $\mathrm{Ca}_{3} \mathrm{SiO}_{5}$. Am Ceram Soc 1973;56:73-9. 
[35] Midgley HG. The determination of calcium hydroxide in set Portland cements. Cem Concr Res 1979;9:77-82.

[36] El-Jazairi B. Illston JMA. simultaneous semi-isothermal method of thermogravimetry and derivative thermogravimetry, and its application to cement pastes. Cem Concr Res 1977;7:247-57.

[37] Collepardi M, Ogoumah-Olagot JJ, Skarp U, Troli R. Influence of amorphous colloidal silica on the properties of self-compacting concretes. In: Proceedings of the international conference"challenges in concrete construction, innovations and developments in concrete materials and construction, Dundee, UK. p. 473-83.

[38] Korpa A, Trettin R. Ultra high performance cement-based composites with advanced properties containing nanoscale pozzolans. In: Proceedings of the second international symposium on ultra high performance concrete, Kassel, Germany.

[39] Ferraris CF, Obla KH, Hill R. The influence of mineral admixtures on the rheology of cement paste and concrete. Cem Concr Res 2001;31:245-55.

[40] Neville AM. Properties of concrete. England: ELBS with Addison Wesley Longman; 1996.

[41] Lin KL, Chang WC, Lin DF, Luo HL, Tsai MC. Effects of nano-SiO(2) and different ash particle sizes on sludge ash-cement mortar. J Environ Manage 2008;88:708-14.

[42] Björnström J, Martinelli A, Matic A, Börjesson L, Panas I. Accelerating effects of colloidal nano-silica for beneficial calcium-silicate-hydrate formation in cement. Chem Phys Lett 2004;392:242-8.
[43] Jo B, Kim CH, Tae Gh, Park JB. Characteristics of cement mortar with nano- $\mathrm{SiO}_{2}$ particles. Constr Build Mater 2007;21:1351-5.

[44] Pourjavadi A, Fakoorpoor SM, Khaloo A, Hosseini P. Improving the performance of cement-based composites containing superabsorbent polymers by utilization of nano- $\mathrm{SiO}_{2}$ particles. Mater Des 2012;42:94-101.

[45] Ghafari E, Costa H, Júlio E, Portugal A, Durães L. Enhanced durability of ultra high performance concrete by incorporating supplementary cementitious materials. In: The 2nd international conference microdurability Delft, Netherland. p. 86-94.

[46] Lo TY, Cui HZ, Nadeem A, Li ZG. The effects of air content on permeability of lightweight concrete. Cem Concr Res 2006;36:1874-8.

[47] Teichmann T, Schmidt M. Influence of the packing density of fine particles on structure, strength and durability of UHPC In: M. Schmidt EF, C. Geisenhanslüke editor. International Symposium on Ultra High Performance Concrete Kassel, Germany September 13-15, 2004.

[48] Heede PVD, Gruyaert E, Belie ND. Transport properties of high-volume fly ash concrete: capillary water sorption, water sorption under vacuum and gas permeability. Cem Concr Compos 2010;32:749-56.

[49] Boel V, Audenaert K, Schutter GD. Gas permeability and capillary porosity of self-compacting concrete. Mater Struct 2008;41:1283-90. 